Int. J. Electrochem. Sci., 11 (2016) $8697-8708$

\title{
The Effect of Commercialized Binders on Silicon Oxide Anode Material for High Capacity Lithium ion Batteries
}

\author{
Haijun Huang ${ }^{1,2}$, Guangshuai Han ${ }^{2}$, Jingying Xie ${ }^{2,3, *}$, Quansheng Zhang, ${ }^{1, *}$ \\ ${ }^{1}$ Department of Chemical Engineering, Shanghai Institute of Technology, Shanghai 200235, China \\ ${ }^{2}$ Shanghai Institute of Space Power Sources, Shanghai 200245, China \\ ${ }^{3}$ Shanghai Power \& Energy Storage Battery System Engineering Tech. Co. Ltd., Shanghai 200240, \\ China \\ *E-mail: jyxie@mail.sim.ac.cn, zhangquansheng@ sit.edu.cn
}

doi: $10.20964 / 2016.10 .29$

Received: 13 July 2016 / Accepted: 11 August 2016 / Published: 6 September 2016

\begin{abstract}
The lithium insertion/extraction properties of silicon oxide $\left(\mathrm{SiO}_{\mathrm{x}}\right)$ composite electrode are investigated using polyvinylidene fluoride (PVDF), LA132 (which major copolymerization chain is polyacrylonitrile-polyacrylic acid (PAN-PAA)) and polyacrylic acid (PAA). Electrochemical cycling tests show that $\mathrm{SiO}_{\mathrm{x}}$ electrode with conventional binder PVDF results in rapid capacity fading, while aqueous binders LA132 and PAA remarkably improve the cycle performance of $\mathrm{SiO}_{\mathrm{x}}$ at a current density of $80 \mathrm{~mA} \cdot \mathrm{g}^{-1} . \mathrm{SiO}_{\mathrm{x}}$ electrode with PAA delivers a reversible capacity up to $1090 \mathrm{mAh} \cdot \mathrm{g}^{-1}$ after 50 cycles. All of the electrodes after 10 cycles exhibiting a huge expansion of surface morphology, and some crevices are observed in $\mathrm{SiO}_{\mathrm{x}}-\mathrm{PVDF}$ electrode. Results of Fourier Transform Infrared Spectroscopy (FTIR) and X-ray diffraction (XRD) show that amorphous or little crystalline grain structure and ester-like bonds are the key factors of adhesion property for binders in $\mathrm{SiO}_{\mathrm{x}}$ composite electrode. With cycling, impendence of the $\mathrm{SiO}_{\mathrm{x}}$ electrodes with different binders is increasing severely. In addition, the differential capacity plots are used to explain the capacity fading mechanism, the kinetics of electrode process of $\mathrm{SiO}_{\mathrm{x}}$ are not affected by applying different binders.
\end{abstract}

Keywords: Lithium ion battery, Si-based, $\mathrm{SiO}_{\mathrm{x}}$, Binder, High capacity anode

\section{FULL TEXT}

(C) 2016 The Authors. Published by ESG (www.electrochemsci.org). This article is an open access article distributed under the terms and conditions of the Creative Commons Attribution license (http://creativecommons.org/licenses/by/4.0/). 